global longitudinal strain (GLS) is $-13.7 \pm 2.3$ on 3D CMT-FT and $-19.3 \pm 2.7$ on 2D CMR-FT. Global radial strain (GRS) is $45.5 \pm 10.9$ for $3 \mathrm{D}$, compared to $55.1 \pm 14.4$ and $48.0 \pm 13.4$ at the base and mid-ventricular level respectively.

Table 1 displays the inter- and intra-observer variability of each technique. Intra-observer variability was significantly improved by 3D CMT-FT for GCS, whilst inter-observer variability was significantly improved for GCS, GRS and strain rates. No reproducibility differences were identified for GLS.

Discussion Peak strains using 3D FT-CMR is different to 2D normal range values. 3D CMR-FT has superior intra- and inter-observer reproducibility compared with 2D CMR-FT, particularly for GCS and GRS strain, the latter being the principal systolic strain and should improve detection of sub-clinical ventricular dysfunction.

\section{EVALUATION OF PATIENTS WITH LEFT VENTRICULAR THROMBUS USING INTRA-CARDIAC BLOOD VISUALISATION WITH 4D FLOW}

${ }^{1}$ Victoria Stoll* ${ }^{1}$ Aaron Hess, ${ }^{2}$ Jonatan Eriksson, ${ }^{1}$ Malenka Bissell, ${ }^{2}$ Petter Dyverfeldt, ${ }^{2}$ Tino Ebbers, ${ }^{1}$ Saul Myerson, ${ }^{2}$ Carl-Johan Carlhall, 'Stefan Neubauer. 'University of Oxford; ${ }^{2}$ Linkoping University

\subsection{6/heartjnl-2017-311726.111}

Introduction Ventricular thrombus is a serious complication in a subgroup of left ventricular dysfunction (LVD) patients because of the risk of embolisation. Thrombus occurs as a consequence of stasis, hypercoagulability and endothelial injury. There are no reliable predictors for which patients will develop thrombus. 4D flow CMR may allow insights into thrombus formation by intra-cardiac blood flow visualisation. We hypothesise that in patients with LV dysfunction and thrombus, compared to those without thrombus, the residual volume would constitute a similar proportion of the LV end diastolic volume (EDV) but possess less kinetic energy, thereby predisposing the blood to stasis and therefore thrombus formation.

Methods 100 participants (47 LV dysfunction but no thrombus (LVD) patients, $17 \mathrm{LV}$ dysfunction and thrombus patients and 36 controls underwent CMR (Table 1)). LV flow was analysed as 4 components; direct flow, retained inflow, delayed ejection flow and residual volume. Each components volume was calculated in proportion to the EDV. The kinetic energy of the blood per millilitre was summed throughout the cardiac cycle and divided by the cycle length to calculate the average kinetic power. 25 controls, 14 LVD and 14 thrombus patients returned for an interval scan to assess the stability of flow parameters.

Results Both patient groups had significantly increased residual volume (LVD $50 \pm 10 \%$, thrombus $51 \pm 12 \%$ vs $30 \pm 4 \%$ conntrols, p 0.001) and decreased direct flow (LVD $11 \pm 7 \%$, thrombus $16 \pm 10 \%$ vs $38 \pm 4 \%$ controls, p 0.001$)$. There was no difference between the 2 patient groups (Fig 1A). The average kinetic power of the residual volume was significantly higher in the LVD group $(0.55 \pm 0.30 \mathrm{microJ} / \mathrm{ml})$ compared to the thrombus group $(0.38 \pm 0.16 \mathrm{microJ} / \mathrm{ml}, \mathrm{p} 0.02)$ (Fig 1B). No difference between patient groups was seen for the direct flow average kinetic power (Fig 1C). 4D flow parameters were similar between visits with no significant change on paired t-tests (Table 2). The average kinetic power of the residual volume was higher in the LV dysfunction than thrombus group at visit 1 and 2, but failed to reach statistical significance with the smaller cohorts.

Discussion The residual volume blood of thrombus patients possessed less kinetic power than that of LV dysfunction patients with a well matched LV size, impairment and

Abstract 112 Table 1 Clinical characteristics of controls, LV dysfunction and thrombus patients.

\begin{tabular}{|c|c|c|c|c|}
\hline & $\begin{array}{l}\text { Controls } \\
(n=36)\end{array}$ & $\begin{array}{l}\text { LV dysfunction } \\
\qquad(n=47)\end{array}$ & $\begin{array}{l}\text { Thrombus } \\
\text { ( } n=17)\end{array}$ & $\begin{array}{c}\text { P value } \\
\text { (between all } \\
\text { groups) }\end{array}$ \\
\hline \multicolumn{5}{|c|}{ Demographics } \\
\hline Age (yrs) & $57 \pm 12$ & $59 \pm 13$ & $62 \pm 14$ & 0.399 \\
\hline Male, n (\%) & $25(70)$ & $37(79)$ & $13(76)$ & 0.62 \\
\hline IHD, n (\%) & - & $17(36)$ & $13(76)$ & 0.0007 \\
\hline Body mass index $\left(\mathrm{kg} / \mathrm{m}^{2}\right)$ & $25 \pm 4$ & $28 \pm 4$ & $29 \pm 4$ & 0.006 \\
\hline Systolic BP (mmHg) & $134 \pm 20$ & $125 \pm 18$ & $122 \pm 17$ & 0.04 \\
\hline Diastolic BP (mmHg) & $78 \pm 10$ & $71 \pm 11$ & $70 \pm 10$ & 0.004 \\
\hline Heart rate (bpm) & $64 \pm 14$ & $64 \pm 13$ & $68 \pm 15$ & 0.542 \\
\hline \multicolumn{5}{|c|}{ Prognostic markers } \\
\hline BNP (pmol/L) & $7 \pm 5$ & $44 \pm 64$ & $115 \pm 166$ & $<0.0001$ \\
\hline 6 minute walk test $(\mathrm{m})$ & $624 \pm 77$ & $490 \pm 91$ & $476 \pm 99$ & $<0.0001$ \\
\hline $\begin{array}{c}\text { Minnesota Heart Failure } \\
\text { Questionnaire }\end{array}$ & - & $21 \pm 21$ & $15 \pm 16$ & 0.294 \\
\hline \multicolumn{5}{|c|}{ CMR results } \\
\hline LVEF (\%) & $67 \pm 4$ & $37 \pm 10$ & $38 \pm 15$ & $<0.0001$ \\
\hline LVEDV (ml) & $159 \pm 31$ & $257 \pm 101$ & $239 \pm 95$ & $<0.0001$ \\
\hline Left atrial EF (\%) & $56 \pm 6$ & $40 \pm 11$ & $36 \pm 17$ & $<0.0001$ \\
\hline LV sphericity index & $1.7 \pm 0.2$ & $1.4 \pm 0.2$ & $1.5 \pm 0.2$ & $<0.0001$ \\
\hline $\begin{array}{l}\text { Mid LV short axis peak systolic } \\
\text { circumferential strain (\%) }\end{array}$ & $-19 \pm 3$ & $-10 \pm 4$ & $-13 \pm 4$ & $<0.0001$ \\
\hline $\begin{array}{l}\text { Mid LV short axis peak diastolic } \\
\text { circumferential strain rate }\left(\mathbf{s}^{-1}\right)\end{array}$ & $83 \pm 19$ & $49 \pm 20$ & $54 \pm 19$ & $<0.0001$ \\
\hline
\end{tabular}


Abstract 112 Table 2 Results for conventional and 4D flow cardic remodelling parameters for participants who attended two study visits. There were no significant differences between visit 1 and visit 2 when paired t-tests were performed for each participant for the parameters shown above.

\begin{tabular}{|c|c|c|c|c|c|c|}
\hline & \multicolumn{2}{|c|}{$\begin{array}{l}\text { Controls } \\
(n=25)\end{array}$} & \multicolumn{2}{|c|}{$\begin{array}{l}\text { LV dysfunction } \\
\qquad(\mathrm{n}=14)\end{array}$} & \multicolumn{2}{|c|}{$\begin{array}{l}\text { Thrombus } \\
(\mathrm{n}=14)\end{array}$} \\
\hline & Visit 1 & Visit 2 & Visit 1 & Visit 2 & Visit 1 & Visit 2 \\
\hline $\begin{array}{l}\text { Days between visits, median } \\
\text { (IQR) }\end{array}$ & \multicolumn{2}{|c|}{$52(28-57)$} & \multicolumn{2}{|c|}{$329(193-511)$} & \multicolumn{2}{|c|}{$334(165-522)$} \\
\hline EF (\%) & $67 \pm 4$ & $66 \pm 4$ & $41 \pm 9$ & $42 \pm 9$ & $42 \pm 13$ & $44 \pm 11$ \\
\hline LV EDV (ml) & $156 \pm 32$ & $159 \pm 33$ & $220 \pm 70$ & $214 \pm 64$ & $214 \pm 62$ & $212 \pm 54$ \\
\hline Residual volume (\% of EDV) & $31 \pm 4$ & $30 \pm 4$ & $46 \pm 10$ & $49 \pm 10$ & $49 \pm 10$ & $46 \pm 9$ \\
\hline $\begin{array}{l}\text { Residual volume average kinetic } \\
\text { power (microJ/ml) }\end{array}$ & $0.36 \pm 0.14$ & $0.35 \pm 0.13$ & $0.48 \pm 0.18$ & $0.41 \pm 0.12$ & $0.34 \pm 0.15$ & $0.35 \pm 0.11$ \\
\hline Direct flow ( $\%$ of EDV) & $38 \pm 4$ & $39 \pm 4$ & $13 \pm 9$ & $13 \pm 8$ & $17 \pm 10$ & $17 \pm 8$ \\
\hline $\begin{array}{l}\text { Direct flow average kinetic } \\
\text { power (microl } / \mathrm{ml})\end{array}$ & $5.0 \pm 1.5$ & $4.8 \pm 1.3$ & $4.5 \pm 1.9$ & $4.6 \pm 1.8$ & $4.3 \pm 1.2$ & $4.4 \pm 1.3$ \\
\hline
\end{tabular}

A)

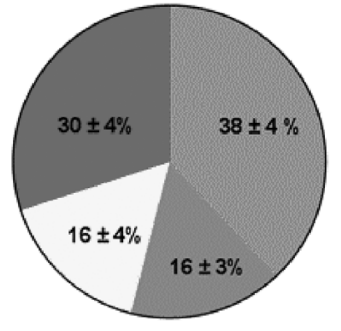

i) Control

B)

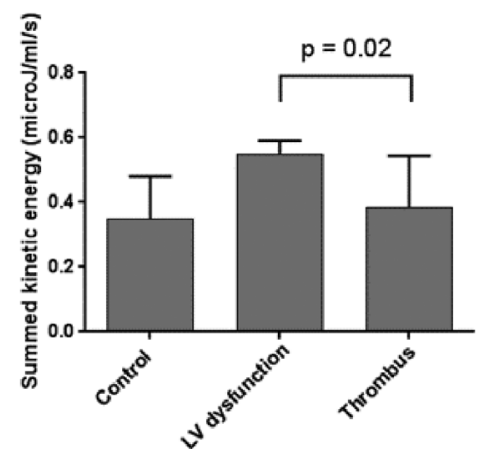

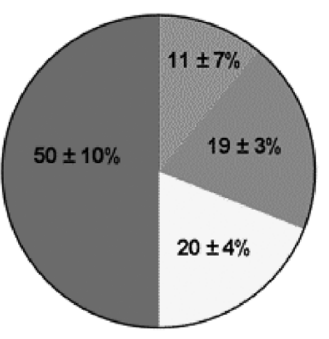

ii) LV dysfunction

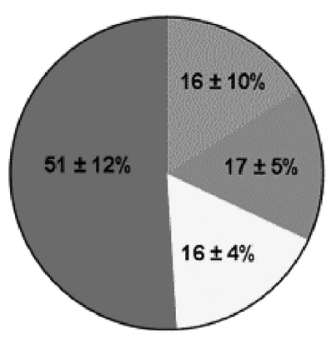

iii) Thrombus

C)

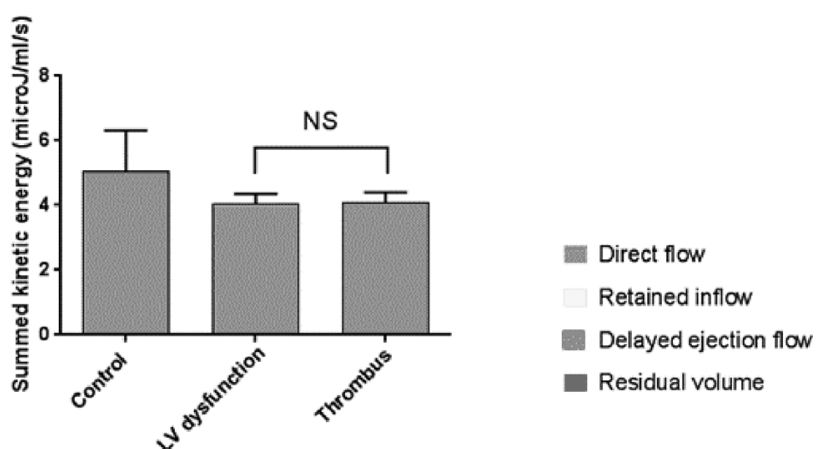

Abstract 112 Figure 1 A) The volume of the four flow components by mean percentage $\pm S D$ in relation to the end diastolic volume. There is increased residual volume and decreased direct flow in the LV dysfunction and thrombus groups compared to controls. B) The residual volume summed kinetic energy per millilitre, normalised to duration of heart cycle for each group. The LV thrombus group have significantly lower residual volume summed kinetic energy, compared to the LV dysfunction group. C) Direct flow summed kinetic energy; no difference is seen between the LV dysfunction and thrombus groups.

proportion of residual volume. Residual volume blood resides within the ventricle for at least two cardiac cycles; reduced movement of this blood component may be a contributing factor to stasis and hence thrombus formation. Similar results at interval studies propose that the residual volume average kinetic power is a temporally stable parameter.
This study suggests that the average kinetic power of the residual volume is a novel imaging biomarker which may allow identification, monitoring and potentially aid anticoagulation decisions in patients with LV dysfunction at higher risk of thrombus formation. 